\title{
Endoscopic Removal of a Proximally Migrated Metal Stent during Balloon Sweeping after Stent Trimming
}

\author{
Nam Jun Cho, Tae Hoon Lee, Sang-Heum Park, Han Min Lee, Kyung Hee Hyun, Suck-Ho Lee, \\ II-Kwun Chung and Sun-Joo Kim \\ Department of Internal Medicine, Soonchunhyang University Cheonan Hospital, Soonchunhyang University College of Medicine, Cheonan, Korea
}

\begin{abstract}
Placement of a self-expanding metal stent (SEMS) is an effective method for palliation of a malignant biliary obstruction. However, metal stents can cause various complications, including stent migration. Distally migrated metal stents, particularly covered SEMS, can be removed successfully in most cases. Stent trimming using argon plasma coagulation may be helpful in difficult cases despite conventional methods. However, no serious complications related to the trimming or remnant stent removal method have been reported due to the limited number of cases. In particular, proximal migration of a remnant fragmented metal stent after stent trimming followed by balloon sweeping has not been reported. We report an unusual case of proximal migration of a remnant metal stent during balloon sweeping following stent trimming by argon plasma coagulation. The remnant metal stent was successfully removed with rotation technique using a basket and revised endoscopically.
\end{abstract}

Key Words: Pancreatic neoplasms; Stents; Cholangiopancreatography, endoscopic retrograde; Argon plasma coagulation

\section{INTRODUCTION}

Biliary stents are widely used for palliation of malignant biliary obstructions. Self-expanding metal stent (SEMS) have a longer patency than plastic stents and offer adequate palliation in patients with an unresectable malignant distal bile duct obstruction. ${ }^{1}$

However, SEMSs and plastic stents may cause complications such as stent migration, tumoral or nontumoral reocclusion, stent-induced ulceration, duodenal obstruction, perforation, and upper gastrointestinal bleeding. ${ }^{2-5}$ In particular, covered SEMS (cSEMS) tend to migrate more frequently than uncovered SEMS (uSEMS). To resolve these complications, several techniques for SEMS removal have been described in the literature. SEMS were successfully removed by using a polypectomy snare, large-mouthed rat tooth forceps, biopsy forceps

Received: May 25, 2012 Revised: June 19, 2012

Accepted: June 23, 2012

Correspondence: Tae Hoon Lee

Division of Gastroenterology, Department of Internal Medicine, Soonchunhyang University Cheonan Hospital, Soonchunhyang University College of Medicine, 31 Suncheonhyang 6-gil, Dongnam-gu, Cheonan 330-930, Korea Tel: +82-41-570-3662, Fax: +82-41-574-5762, E-mail: thlee9@schmc.ac.kr

(c) This is an Open Access article distributed under the terms of the Creative Commons Attribution Non-Commercial License (http://creativecommons.org/ licenses/by-nc/3.0) which permits unrestricted non-commercial use, distribution, and reproduction in any medium, provided the original work is properly cited. or an endoscopic suture-cutting device. ${ }^{6-9}$ Although removal of these complicated cSEMS is usually successful and easier than removing a uSEMS in most cases, some cases of cSEMS may be difficult to remove using conventional methods. ${ }^{6-11}$ Several studies have reported that difficult cases of distally migrated SEMS can be treated by argon plasma coagulation (APC) trimming. However, there has been no report about endoscopic removal of proximally migrated, trimmed SEMS during balloon sweeping after APC trimming, which may be difficult to handle using conventional methods.

We report an unusual complicated case of proximal migration of a remnant metal stent during balloon sweeping following complete stent trimming by APC, the case which was successfully removed by using a basket and revised endoscopically.

\section{CASE REPORT}

A 74-year-old woman was admitted due to jaundice and epigastric pain which lasted for 7 days. Laboratory tests revealed the following: white blood cell count, $5.84 \times 10^{9} / \mathrm{L}$ (reference range, 4.0 to $10.8 \times 10^{9} / \mathrm{L}$ ); aspartate aminotransferase, 123 IU/L; alanine aminotransferase, $144 \mathrm{IU} / \mathrm{L}$; total bilirubin, 5.2 $\mathrm{mg} / \mathrm{dL}$; alkaline phosphatase, $488 \mathrm{IU} / \mathrm{L}$; amylase, $315 \mathrm{U} / \mathrm{L}$; lipase, $689 \mathrm{U} / \mathrm{L}$; carbohydrate antigen 19-9, $35.86 \mathrm{U} / \mathrm{mL}$; and 
carcinoembryonic antigen, $1.65 \mathrm{ng} / \mathrm{mL}$. An abdominal computed tomography scan showed a $\sim 2.1-\mathrm{cm}$ low-attenuated mass lesion abutting on the superior mesenteric vein with dilatation of the intrahepatic bile duct, common bile duct (CBD) and pancreatic duct (PD), which suggested pancreas neoplasm. Subsequent endoscopic retrograde cholangiopancreatography (ERCP) showed short segmental distal CBD narrow- ing and diffuse irregular narrowing of the PD with marked upstream ductal dilatation (Fig. 1). After a 5-Fr single pigtail 7-cm-long stent was inserted into the PD following brushing cytology and an 8.5-Fr Tannenbaum, 7-cm-long (Cook Endoscopy, Winston-Salem, NC, USA) stent was inserted into the CBD, her symptoms improved and the obstructive jaundice resolved. Finally, we diagnosed her as a pancreas adenocarci-
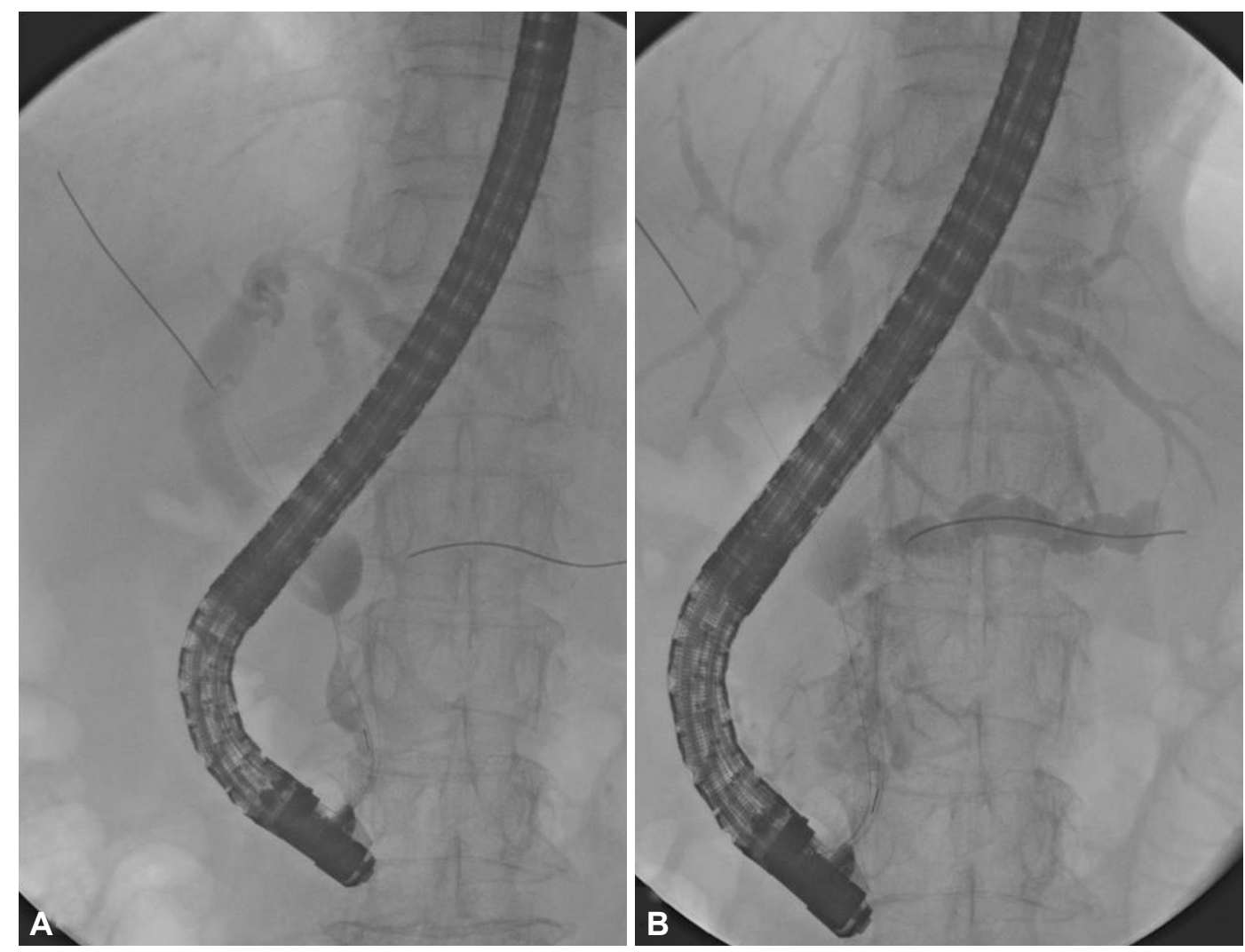

Fig. 1. Endoscopic retrograde cholangiopancreatography findings. (A) About 1.5-cm-long short segmental distal common bile duct narrowing with upstream bile duct dilatation. (B) Diffuse irregular narrowing of the pancreatic duct (PD) with marked upstream PD dilatation.
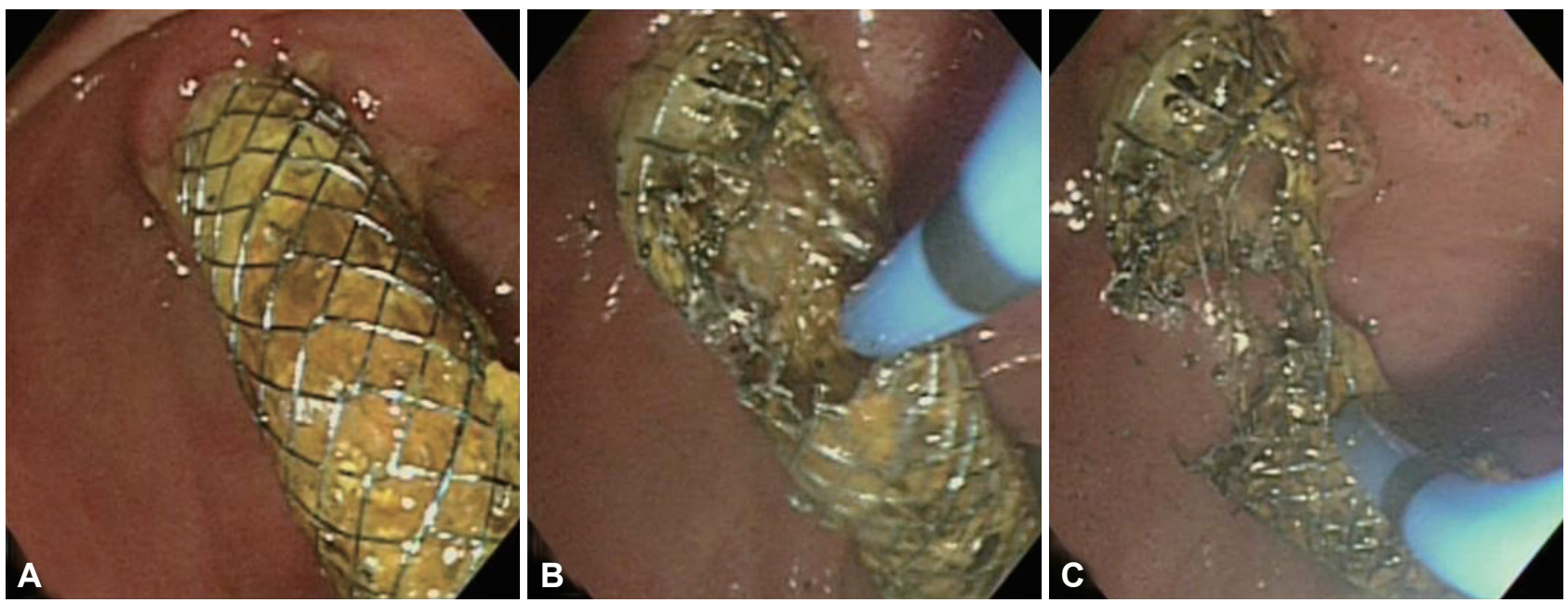

Fig. 2. Duodenoscopic findings. (A) Partial distally migrated biliary covered self-expanding metal stent (cSEMS). (B) Stent trimming by argon plasma coagulation. (C) Completely fragmented cSEMS stent after trimming. 
noma with $\mathrm{CBD}$ obstruction.

Two months later, she underwent repeat ERCP for stent exchange using a 60-mm-long, 10-mm diameter cSEMS (Bonastent; Standard Sci Tech Inc., Seoul, Korea), because she re- fused surgical operation. However, she was readmitted in 2 months due to epigastric pain, fever, and jaundice. A subsequent endoscopy showed a partial distally migrated cSEMS that was impossible to access and revise through the migrated stent.
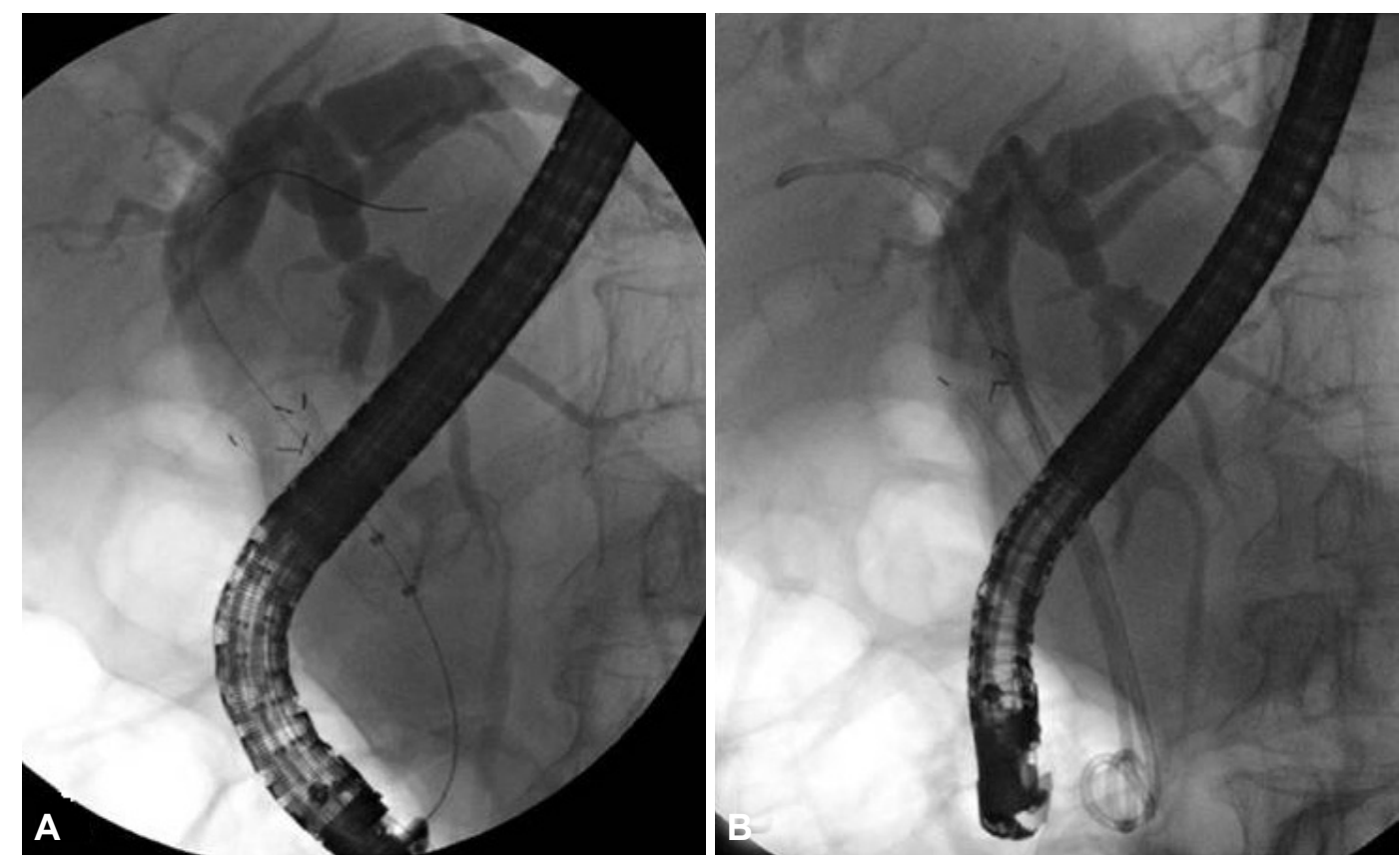

Fig. 3. Endoscopic retrograde cholangiopancreatography findings. (A) The proximally migrated metal stent after trimming, and the guidewire passed through the migrated stent. (B) Two 7-Fr double-pigtail stents were inserted into both intrahepatic ducts through the migrated stent.
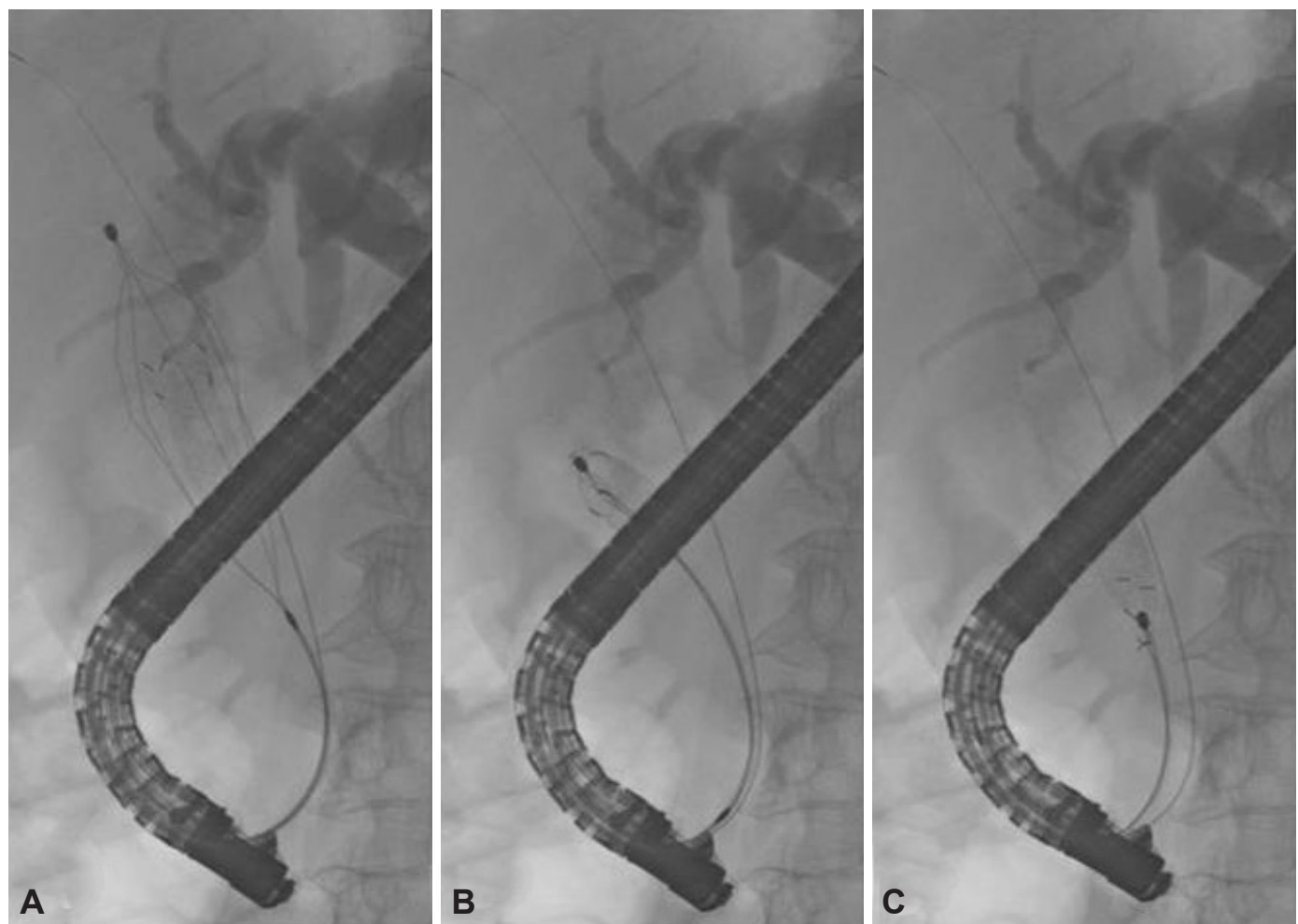

Fig. 4. Endoscopic retrograde cholangiopancreatography finding of migrated stent removal. (A) The proximally migrated stent was floating in the common bile duct and was captured with a Dormia basket. (B) The proximal portion of the floating stent was captured by the basket and then rotated $180^{\circ}$ in the common bile duct. (C) The stent was retrieved from its proximal end after complete rotation. 


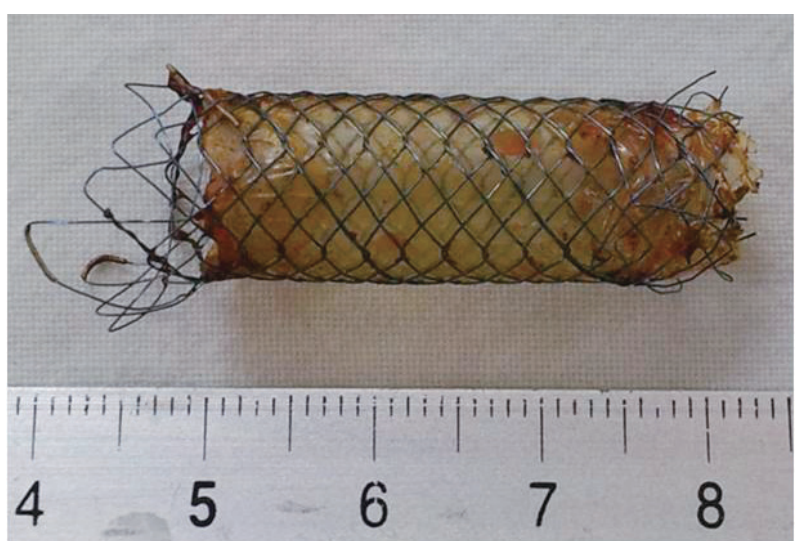

Fig. 5. Gross appearance of the proximally migrated amputated covered self-expanding metal stent.

We decided to remove the stent but failed with forceps and a snare.

Thus, stent trimming was performed with an APC system (ERBE Elektromedizin GmbH, Tübingen, Germany). The power setting was $60 \mathrm{~W}$, and the argon gas flow was set to $2 \mathrm{~L} /$ $\mathrm{min}$. The amputated stump margin was set about $10 \mathrm{~mm}$ from the papilla. Stent amputation progressed in a circumferential manner until it was completely cut after 10 minutes (Fig. 2). The stent fragment was removed with a retrieval net. Then, a retrieval balloon was used to remove the clogging sludge following insertion of a guidewire through the remnant fragmented stent. However, while moving the balloon back and forth, the remnant stent migrated proximally very abruptly and floated to the dilated CBD. Immediate retrieval of the stent was not attempted because of the sharp cutting plane edge. Two 7-Fr double pigtail stents (9- and 10-cm long, respectively; Cook Endoscopy) were inserted in both intrahepatic bile ducts through the proximally migrated metal stent (Fig. 3). However, the patient was readmitted twice because of cholangitis and obstructive jaundice after 1 month, so removal of the proximally migrated metal stent was planned. Following removal of the double pigtail stent with rat tooth forceps, the stricture was dilated to $8 \mathrm{~mm}$ with a balloon catheter (Hurricane biliary balloon dilatation catheter; Boston Scientific, Natick, MA, USA). The proximal end of the floating metal stent was captured with a basket, rotated $180^{\circ}$ in the $\mathrm{CBD}$, and then removed successfully (Figs. 4, 5). No procedure related complications occurred during the removal of the migrated stent, and then a uSEMS was inserted successfully. Since then, no complications have been observed for 5 months.

\section{DISCUSSION}

SEMS placement has the advantage of greater long-term patency and cost-effectiveness compared to placement of a plastic stent for the palliative treatment of malignant distal biliary strictures. ${ }^{1,2}$ Nevertheless, some complications, such as occlusions and migration of SEMS, can be problematic. Proximal migration is a less common mode of migration and less frequently reported by other investigators. There was limited number of cases about removal of proximally migrated SEMS and also these migrated stents had a normal configuration. Bakhru et al. ${ }^{12}$ reported one patient who experienced proximal migration 58 days following cSEMS insertion but did not describe retrieval technique. Ho et al. ${ }^{13}$ reported that proximal migration of partially covered SEMS occurred in seven cases (1.7\%), and migrated stents was extracted by balloon dilation combined with rat tooth extraction.

Unlike plastic stents, SEMSs are relatively hard to extract after being inserted and fixed. Endoscopic removal has been successfully achieved in selected cases, particularly when a cSEMS was the issue. ${ }^{6-8}$ Several techniques for SEMS removal have been described in the literature. Kahaleh et al. ${ }^{9}$ successfully removed a SEMS using a polypectomy snare and largemouthed, rat tooth forceps. uSEMSs have been removed using 'hot' biopsy forceps to extract individual wire filaments from the distal end. Levy and Wiersema ${ }^{14}$ removed a distally migrated biliary Wallstent using an endoscopic suture-cutting device. Even with cSEMSs, only $4.5 \%$ to $22.2 \%$ of cases are limited by removal of the stent. ${ }^{6,9}$

APC has been used successfully to trim SEMS in selected patients, particularly in cases where the prolapsing part of the stent is extremely long and cannot be held with a snare or holding forceps. The safety and usefulness of APC trimming have been confirmed in experimental and clinical studies. ${ }^{6,10,11,15,16}$ Similarly, we used an APC trimming method in our case, because the SEMS was partially distally migrated, and we failed to remove the stent with a snare and forceps. However, in our case, the remnant stent migrated proximally and was difficult to remove because of sharp cutting plane edge. The proximal migration of a remnant stent might be explained by various factors. First, excessive balloon sweeping inside the remnant stent to remove sludge might have facilitated stent migration. Second, as a predisposing factor, the decreased frictional force between the metal stent and the stented CBD wall due to thermal injury by APC trimming might facilitate migration. In an animal study, which reported gross and histological findings after biliary stent trimming, APC stent trimming had the potential to cause superficial tissue damage by heat transmission through the treated metal stent. ${ }^{15}$ In these circumstances, excessive balloon sweeping might have facilitated stent migration. Third, relatively short length of malignant stricture due to pancreas malignancy might be an additive factor for proximal migration. Accordingly, after trimming a metal stent, excessive balloon sweeping inside the stent should be performed with caution, particularly with cSEMS. 
Retrieval techniques for removal of proximally migrated plastic and metal stents include forceps, a Dormia basket, snare, balloon, and a Soehendra stent retriever. ${ }^{12,17,18}$ A migrated stent may cause frequent cholangitis, as in our case, even if endoscopic revision is successful. Although two plastic stents were inserted through the migrated metal stent, cholangitis developed twice within 2 months. A remnant stent may affect bile flow and more frequently clog the stent. In our case, the basket-capture technique was used to retrieve the migrated metal stent. After capturing the proximal end of the migrated stent with a basket, the stent was rotated $180^{\circ}$ in the markedly dilated proximal $\mathrm{CBD}$ and then finally removed, as the distal end of the stent was sharp and may have caused bleeding or perforation during passage through the strictured distal CBD. Proximal migration of a remnant stent with sharp cutting plane edge after stent trimming by APC has not been reported in the English literature, making it difficult to establish ideal methods for stent removal. Our method might have also caused injury to the bile duct during rotation if $\mathrm{CBD}$ dilatation was not enough. Folding or crushing with basket or snare can be used for the same purpose. However, considering the sharp edges of cutting plane, our method may be helpful to minimize injury during removal. No complications were observed during the removal of the fragmented stent, and then an uSEMS was placed successfully. As another option, secondary reinsertion of a metal stent through the migrated remnant stent should be considered, if guidewire initially passed through the migrated metal stent.

In conclusion, although endoscopic APC trimming of a distally migrated CSEMS facilitated the removal of the migrated stents that were difficult to remove by conventional methods, a rare complication, such as proximal migration, can develop in association with excessive balloon sweeping in short segmental stricture. When trimming the SEMS to resolve a distal migration, adequate remnant stent material should be ensured to prevent proximal migration during additional endoscopic procedures such as ballooning, particularly with cSEMS. Furthermore, since retrieval of a stent using a basket can be attempted safely, early removal of the migrated stent is necessary to prevent other complications.

\section{Conflicts of Interest}

The authors have no financial conflicts of interest.

\section{REFERENCES}

1. Davids PH, Groen AK, Rauws EA, Tytgat GN, Huibregtse K. Randomised trial of self-expanding metal stents versus polyethylene stents for distal malignant biliary obstruction. Lancet 1992;340:1488-1492.

2. Kahaleh M, Tokar J, Conaway MR, et al. Efficacy and complications of covered Wallstents in malignant distal biliary obstruction. Gastrointest Endosc 2005;61:528-533.

3. Pescatore P, Meier-Willersen HJ, Manegold BC. A severe complication of the new self-expanding spiral nitinol biliary stent. Endoscopy 1997; 29:413-415.

4. Thumbe VK, Houghton AD, Smith MS. Duodenal perforation by a Wallstent. Endoscopy 2000;32:495-497.

5. Roebuck DJ, Stanley P, Katz MD, Parry RL, Haight MA. Gastrointestinal hemorrhage due to duodenal erosion by a biliary wallstent. Cardiovasc Intervent Radiol 1998;21:63-65.

6. Ishii K, Itoi T, Sofuni A, et al. Endoscopic removal and trimming of distal self-expandable metallic biliary stents. World J Gastroenterol 2011; 17:2652-2657.

7. Shin HP, Kim MH, Jung SW, et al. Endoscopic removal of biliary selfexpandable metallic stents: a prospective study. Endoscopy 2006;38: 1250-1255.

8. Familiari P, Bulajic M, Mutignani M, et al. Endoscopic removal of malfunctioning biliary self-expandable metallic stents. Gastrointest Endosc 2005;62:903-910.

9. Kahaleh M, Tokar J, Le T, Yeaton P. Removal of self-expandable metallic Wallstents. Gastrointest Endosc 2004;60:640-644.

10. Christiaens P, Decock S, Buchel O, et al. Endoscopic trimming of metallic stents with the use of argon plasma. Gastrointest Endosc 2008;67: 369-371.

11. Vanbiervliet G, Piche T, Caroli-Bosc FX, et al. Endoscopic argon plasma trimming of biliary and gastrointestinal metallic stents. Endoscopy 2005; 37:434-438.

12. Bakhru M, Ho HC, Gohil V, et al. Fully-covered, self-expandable metal stents (CSEMS) in malignant distal biliary strictures: mid-term evaluation. J Gastroenterol Hepatol 2011;26:1022-1027.

13. Ho H, Mahajan A, Gosain S, et al. Management of complications associated with partially covered biliary metal stents. Dig Dis Sci 2010;55: 516-522.

14. Levy MJ, Wiersema MJ. Endoscopic removal of a biliary Wallstent with a suture-cutting device in a patient with primary pancreatic lymphoma. Endoscopy 2002;34:835-837.

15. Chen YK, Jakribettuu V, Springer EW, Shah RJ, Penberthy J, Nash SR. Safety and efficacy of argon plasma coagulation trimming of malpositioned and migrated biliary metal stents: a controlled study in the porcine model. Am J Gastroenterol 2006;101:2025-2030.

16. Cho JH, Dong SH, Cho CH, et al. A case of argon plasma trimming of a biliary metallic stent causing a duodenal obstruction. Korean J Gastrointest Endosc 2011;42:195-200.

17. Katsinelos P, Kountouras J, Paroutoglou G, et al. Migration of plastic biliary stents and endoscopic retrieval: an experience of three referral centers. Surg Laparosc Endosc Percutan Tech 2009;19:217-221.

18. Chaurasia OP, Rauws EA, Fockens P, Huibregtse K. Endoscopic techniques for retrieval of proximally migrated biliary stents: the Amsterdam experience. Gastrointest Endosc 1999;50:780-785. 